\title{
A poesia entrevista: uma bio-grafia de Armando Freitas Filho
}

Marcelo Diniz

o câmbio macio ou brusco do pensamento

trocando de marcha e de plano.

Armando Freitas Filho
A poesia reunida e revista de Armando Freitas Filho, lançada neste ano de 2003, recebe um título próprio: Máquina de escrever*. Trata-se de um título em que concorrem dois aspectos de sentido extremamente pertinentes à poética de Armando: $\mathrm{o}$ caráter maquínico de uma pulsão da escrita em tensão com o próprio instrumento da escrita concebido como engenho mecânico e ruidoso, extensão do corpo. Esse caráter pulsional pode ser confirmado no serialismo que configura a primeira parte do livro: Numerais. A tensão entre o número e o infinito que esta série configura parece reproduzir a mesma tensão do desejo prismado pela metáfora da máquina de escrever. Máquina de escrever, poesia reunida e revista sugere-nos um convite a um livro paradoxal, ou ainda, a uma obra que faz do paradoxo o seu mecanismo de expansão. Este texto pretende uma abordagem movida não só pela curiosidade como também pelo prazer parcial e fundamental que toda borda oferece como zona erógena. É como borda poética que se pretende interpretar a entrevista que o autor concedeu a Adolfo Montejo Navas* para a Revista Cult, $n^{\circ} 40$. Borda de quem lê e escreve, e borda também de uma obra de singular referência na poesia brasileira contemporânea.

A entrevista, devido à natureza mesma do étimo desse termo, implica a interlocução, a boa vontade da troca de informações. A entrevista parece basear-se na idéia de um espaço de neutralidade comunicacional, em que os termos a serem cambiados e os sujeitos que os cambiam encontram-se muito bem delimitados, e, devido a esse traço oral da simultaneidade de interlocutores, parece consistir também num espaço de oportunidade especulativa, esclarecimento demandado a alguma
" (Filho, Armando Freitas. Máquina de escrever-poesia reunida e revista. Rio de Janeiro, Nova Fronteira, 2003: 607)

* (Navas, Adolfo Montejo. Entrevista - Armando Frei tas Filho. Em: Cult-Revista brasileira de literatura, $\mathrm{n}^{\circ}$ 40, Ano IV, São Paulo. 2001: 04-11) 
autoridade ou testemunha. Acredito que seja essa a geometria elementar que promove o espaço híbrido entre a escrita e a fala, em que a escrita tem o mero papel de registro, grau zero de corporeidade, sem temporalidade própria, num cenário que, por ser mais próximo à fala, parece prometer-nos ser mais próximo à idéia, pelo menos à idéia de literalidade que, porventura, possua um discurso. Acredito que de alguma forma somos dotados dessa elementar ingenuidade assim que voltamos nossos olhos a essa forma dissimulada de escrita, mesmo em se tratando dos temas mais ambíguos, mesmo ainda em se tratando dos temas em que a ambigüidade da linguagem é a grande celebridade do discurso, como no caso de entrevistas de poetas. No entanto, algumas observações no que diz respeito à entrevista de poetas podem transtornar essa ingenuidade a ponto de se conceber a entrevista como um espaço contaminado.

A entrevista como um gênero literário? Nada disso! A entrevista como um espaço de contaminação da escrita, como um espaço em que a escrita, viva, pendendo irresistivelmente às suas polimorfoses incuráveis, contrabandeia as fronteiras convenientes da teoria entre o eu-lírico e o eu-biológico através de um eu-bio-gráfico, um eu em flagrante vida-escrita. Afinal, é inegável essa pequena curiosidade que deve, acredito, acometer até mesmo ao mais higiênico dos críticos quando interessado pelo registro do discurso direto e imediato, esse pouco tempo da resposta a que se submete o escritor tão difuso em própria obra e crítica. Como não esperar da entrevista uma chave a mais, uma confirmação disso mesmo que aos poucos deixa de pertencer somente ao autor, que paira ao seu redor como um diálogo, dispersão de cifras que na entrevista pode, a qualquer momento, confirmar as íntimas especulações dos envolvidos no assunto? Fora o que aparentemente é menor, mas que, com mais atenção, parece se dirigir a certo enigma de toda obra, o fator biográfico, certo prazer com o inusitado acontecimento in vivo da obra através daquele que a escreve, sua cozinha, suas manias, os caprichos da musa que o domina.

A entrevista de Armando Freitas Filho parece-nos dar um precioso exemplo dessa possibilidade do paraliterário não como privação do poético, como costumeiramente se concebe esse termo, mas como disseminação do espaço da escrita, maquinação da própria poética em sua metodologia de infiltração e descontrole. Ao olho acostumado à fluência prosódica da fala, ao 
deslizamento sintático do ouvido de que se investe o olho ao ler uma entrevista, salta-nos aos olhos, logo a princípio, não somente a extensão das respostas, mas, sobretudo, a sintaxe própria da escrita poética de Armando, prenunciando as vertigens de elipses, cortes e suspensão de sentido tão presentes no cinetismo de seus poemas, tão logo lidas as duas primeiras frases da primeira resposta:

Se não antes do pensamento, ao menos atrás dele, nos dois sentidos: encoberto em perseguição. Tentando emparelhar-se com ele, esforçando-se para que o tex to seja impregnado por sua fluidez característica, ao mesmo tempo em que se luta para se desembaraçar de seu plano diretor. Na verdade, é um projeto utópico, pois visa dar visibilidade ao invisível, matéria ao imaterial por natureza. Mas, já que a poesia pretende ser um acontecimento da inteligência, dentro desse espaço de especulação é bem-vinda, e ir ao encalço de utopia pode ser considerado, portanto, com alguma boa vontade, ocupação sensata e produtiva.

A dinâmica da escrita, sua fuga contrapontística entre a poesia e o pensamento, parece se reproduzir em corpo presente, ou seja, na organicidade mesma do plano expressivo da mensagem. O corpo é contaminado em sua sintaxe. A demanda de limpidez de sentido entre o pensamento e a poesia é dirigida à frase, esse organismo relativamente autônomo que a entrevista, pela sua própria natureza não-literária, busca flagrar em naturalidade, despojada dos artifícios da equivocação poética. A entrevista parece-nos prometer, parece mesmo ser mobilizada por essa fantasia, a metalinguagem, o entender do autor como um terceiro em relação à sua obra, um primeiro e mais avalizado leitor, que partilharia conosco a boa vontade da linguagem em comunicar; no entanto, a resposta de Armando parece não ceder a essa tentação, tão irremediavelmente se encontra o discurso do poeta nessa perseguição, impregnado por sua fluidez característica. ${ }^{1}$ O contraponto é duplicado, a sintaxe contaminada da resposta parece se expandir para toda a arquitetura previsível do texto-entrevista, desnaturalizando o discurso e as expectativas de deciframento que são alimentadas por esse espaço. Resposta e pergunta parecem atender menos à lógica de um diálogo que à de mais um espaço de especulação, encalço de utopias, que

\footnotetext{
${ }^{1}$ Todos os trechos em itálico, a partir desse ponto, são expressões extraídas da entrevista.
} 
conferem ao espaço dialógico da entrevista a experiência da dinâmica da própria poética abordada, acontecimento de inteligência.

É por esses indícios sintáticos, elípticos, metafóricos, que se vislumbra a natureza em ato desse eu bio-gráfico. Menos nas considerações gerais ou conceituais sobre a poesia ou o conteúdo abordado, mais no caráter gestual que se assoma à construção frasal que aos poucos se entorta ou ao vocabulário, a bio-grafia, essa escrita viva, é flagrada como um corpo irredutível, entrevisto na esguelha entre o sensível e o sentido. É o que se vislumbra na resposta à segunda pergunta, em que toda uma semântica muito pertinente à obra abordada assalta a leitura e, de novo, leva a literalidade à vertigem:

Sem querer generalizar muito, acho que a matéria poética - de qualquer matéria poética digna desse nome - quase sempre acaba sendo construída na entrelinha, com o que não é dito nem escrito nos media, com o que se irradia quase em segredo para uma audiência pequena, mas feroz, com ouvido fino de bicho ou sensor de morcego que capta, enfim, essa vibração que vai passando impercebida $[\ldots]$.

Do conceitual, do genérico, da palpável matéria simbólica - de qualquer matéria digna desse nome -, o longo período metamorfoseia o literal em literário, chegando à audiência feroz, cujo adjetivo elabora a vertigem imagética - ouvido fino de bicho ou sensor de morcego - de semântica animal, sensória, orgânica, tão pertinente à escrita da obra abordada. É com essa metamorfose, do registro literal ao literário, que a sintaxe da resposta parece inscrever em seu próprio curso a temporalidade do gerúndio, a tal fluidez característica do ser em ato da escrita poética que vaipassando impercebida. A escrita parece aflorar dessa dinâmica entre o ouvido e o olho, entre a fala e a grafia, o eu que diz e o eu que escreve, a dupla dimensão implicada nesse espaço de entrevista, abordando essa vibração entre uma forma expressiva e outra, não como representação esclarecedora, mas sugestionando-nos, conduzindo-nos, na própria tensão do discurso, aos indícios do imponderável, a poesia. Diante do indizível que não cessa de se dizer, uma poética de indícios: não à toa a recorrência à imagem orgânico-sensorial do morcego, cego de ouvido fino, atento ao negativo - entrelinha - da escrita, a entrevista de Armando não esclarece o enigma de sua poética, duplica-o, tal uma ferocidade inalienável da escrita poética. 
A escrita encontra-se envolvida com uma poética da aporia, uma paradoxologia - a matéria poética [...] quase sempre acaba na entrelinha, com o que não é dito nem escrito - que não reconhece os limites de espaço nem de registro e se expande na entrevista, perturba esse espaço, desnivela sua gramática, não aceita ser apenas objeto, assunto, insiste e contamina o logos reflexivo sobre a poesia. Parece ser essa cifragem que ausculta o ouvido fino quando atento à articulação do sentido, do conceitual ao metafórico, da imagem simbólica à que iconiza o indicial, que se revela em maior pureza com o substantivo vibração impercebida, pura ocorrência material, sem nome, em puro ato. Parece ser à sintaxe desse processo que nos leva o ritmo de uma frase longa, até à metade em unidades de sentido de longa a média, bem ao padrão da fala corrente, mas que aos pouco se entrecorta, justamente quando as metáforas se desdobram, através de duas pequenas unidades entre vírgulas, uma adversativa mas feroz - e outra adverbial conclusiva - enfim. Sem se falar na assonância, essa figura sintática de vogais, que dá início às imagens da metáfora - ouvido fino de bicho - quase iconizando aos ouvidos de quem lê o silvo agudo e os ecos do morcego em pleno vôo no escuro de si mesmo.

Uma outra passagem, extremamente pertinente à especulação do espaço da escrita, é a resposta à terceira pergunta, a que se dirige ao processo de criação poética de Armando. Vale a leitura: A poesia "chega" para mim descontinuadamente. O caderno, a folha casual (mais esta do que aquele), o pedaço de papel (mais este do que aquela) condicionam o que escrevo, forçosamente. Afinal, o suporte acaba por influir no que vai "suportando". Como esse pedaço de papel não tem "estatuto" nenhum (se tiver será o de um "volante" passado de mão em mão), o poema se estrutura nesse lugar instável, trêmulo. Quando se fixa através da escrita, primeiro à mão, depois à máquina de escrever mecânica, e, agora (estágio recente), na tela do computador, traz na sua composição essa incerteza. Aliás, com o advento do computador o ciclo da criação, digamos assim, se fecha, pois parece que volto ao começo de tudo, já que escrever nele é como escrever na água do pensamento, quando tudo pode ser, de repente, apagado, reformado, absolvido, sem deixar marcas, apenas o leve incômodo ou remorso de alguma coisa que se perdeu para sempre [...]

Nesse ponto, a poética do paradoxo se desdobra em uma poética da virtualidade. É nesse ponto ainda que o encalço de utopias 
parece ganhar a corporeidade dinâmica de qualquer lugar, qualquer papel, qualquer media, qualquer suporte, uma vez que o objeto especulado materialmente em escrita sempre se encontra em tensão com o não-material, o não-espacial, uma vez que nenhum topos é detentor de estatuto, a não ser o de volante, fluido, cambiante à medida que o transtorne a vertigem da escrita, quando passado de mão em mão. A utopia é tomada em sua etimologia própria, o não-lugar, e a poesia é concebida pela dinâmica dessa anti-matéria com a materialidade própria do lugar-suporte que possui papel decisivo à medida que vai suportando essa tensão com sua antítese. De novo o gerúndio parece flagrar, através de um simples chiste (suportando $=$ ser suporte de e/ou suportando = tolerando), a temporalidade instantânea da experiência poética, o ser em ato da escrita poética, como uma leve insinuação de vertigem de sentidos no espaço da entrevista. Do paradoxo da inscrição entre esse nãolugar/utopia e lugar-suporte, a entrevista como escrita se oferece à abertura da virtualidade poética, que é entendida, por fim, sob a idéia de ciclo que se inscreve na água do pensamento, cujo incômodo ou remorso é de alguma coisa que se perdeu para sempre, ao que se pode acrescentar subliminarmente alguma coisa que parece insistir para sempre, descontinuadamente como afirma no início da resposta, a poesia que "chega" ou paira, espécie de iminência, Nunca/ nenhum poema acaba, como afirma o poema citado ao fim da resposta.

É dessa lógica do paradoxo que a poética afirma mais uma vez sua temporalidade em ato, sua contemporaneidade como estado em trânsito, inacabado por excelência, na contramão das expectativas, inclusive as do autor, propondo a metodologia do descontrole, que mais uma vez desestabiliza o sujeito do discurso-entrevistado através de um eu-bio-grafado que experimenta essa dinâmica da escrita com o indizível:

João Cabral, poeta fundamental - mas péssima influência quando lido de maneira servil -, tem de ser enfrentado pelos que vêm depois, até para que possamos, por contraste, amá-lo melhor. Para mim, o poema hoje pede um menor controle do autor sobre seus resultados. Só assim se consegue interromper o esperado, o tom didático, monocórdio, a causa e o efeito da escrita cabralina. Um bom poema é sempre aquele que surpreende, em primeiríssimo lugar, ao seu próprio autor. Já não basta, para isso, trocar de mão e catar feijão. É preciso sempre que possível, escrever na contramão de si mesmo. O poema contemporâneo não necessita de 
pontos finais, ele não "acaba”, exatamente. Um certo ar de flash, de flagrante, de acaso, de ambigüidade enfim, são elementos que devem ser recuperados.

É justamente esse imperativo da surpresa que redime o eubiológico, que libera o eu-lírico da estetização do poema, mobilizando um eu-bio-gráfico em uma ética da escrita, um comportamento de atenção às indeterminações da escrita viva na manutenção da consciência de sua temporalidade, uma ética de risco, de permanência e fuga, um uso extremo da saúde provada na afirmação da doença, uma patologia bio-gráfica que encarna o eterno tema da vida como obra. Vale a leitura dessa passagem:

Para o bem ou para o mal, meus poemas, ao longo desse tempo, adquiriram características próprias. Esse seria o gume positivo: todo escritor almeja uma identidade. O outro, antagônico, faz com que procure negar o determinismo desse corte, trazendo para seu risco novas ramificações, mantendo-o vivo, ferido, irrigado, com alternativas, para evitar que se transforme precocemente numa cicatriz repisada e seca. Ou então, tentar adiar ao máximo esse destino. A tensão, muitas vezes apontada em minha poesia, resulta daí, em virtude do movimento contraditório que conjuga, num mesmo corpo, permanência e fuga. É como se procurasse trazer para a metáfora clássica da árvore que cresceu, sabese lá como, através da vida, e antes que ela seja desligada da paisagem, o maior número de ramos que essa árvore pode suportar, e até mesmo, os insuportáveis.

A ambigüidade dos gumes do vivo, entre a identidade e o antagônico movimento de corte, a fim de mantê-lo ferido, irrigado, o eu-bio-gráfico se assume neste movimento contraditório, paradoxal, em que a escrita se constitui como espaço de permanência e fuga, fazendo da entrevista mais um risco de ramificações, fazendoa suportar até mesmo o insuportável. O dado orgânico, imprescindível na poética de Armando Freitas Filho, desdobra, de forma incontinente como uma patologia da escrita em ação, suas metáforas e suas monstruosidades de risco, desestabilizando o espaço de neutralidade suposto pelo registro da entrevista, fazendo desse espaço o corpo expressivo de sua saúde e de sua doença, através da vida, e antes que ela seja desligada da paisagem.

É neste ponto de síntese paradoxal entre a finitude e a infinitude que não só a obra literária, mas a própria entrevista que a aborda podem ser pensadas como a experiência de uma ética da escrita. Ou ainda, é nessa abordagem, a princípio marginal à obra que é a entrevista, que o eu bio-grafado pode lidar com a 
idéia de uma sobrevida ou outra vida de sua escrita. Se, como consideramos, de modo geral, a princípio, a entrevista é movida pela obscenidade na apreensão do sentido, esse registro do discurso parece-nos prometer justamente a finitude do jogo erótico que se experimenta na obra. Sob a fantasia da intersubjetividade, esperam-se do entrevistado determinadas cifras que delimitem, estabilizem a produção de sentido em que sua obra se encontra. No entanto, nesta entrevista especificamente, Armando parece-nos conduzir à continuidade ou irredutibilidade do erotismo da escrita, à própria experiência dramática da infinitude implicada na escrita. Dramática porque tensa e também porque extensiva ao leitor, essa ramificação imponderável do sentido inscrito no erotismo da obra. Como toda ética, a relação com o outro é a própria possibilidade de formulação dessa ética da escrita. Seja em relação à alteridade do leitor, seja mesmo em relação à alteridade de que se pode promover esse espaço da entrevista em relação ao espaço literário, a obra que se pretende inacabada, parcial portanto, insinua sua experiência justamente com a desestabilização desse espaço e desse leitor como uma espécie de imperativo ético implicado pela experiência poética.

A poesia entre-vista pela entrevista é essa interlocução de escrita provocada e provocadora que nos oferece, que proporciona, que contagia a escrita do eu-bio-grafado de Armando Freitas Filho, forçando-nos não só a conceber a vida pela ética da escrita, assim como a entrevista em seu registro de vertigem, poética em ação, a entrevista como espaço possível da escrita poética. 
Poeta e letrista, além de Mestre e doutorando em Ciências da Literatura - Semiologia na Universidade Federal do Rio de Janeiro. Em 2002, publicou os poemas "Agulhas e ócio" na revista Poesia Sempre (Fundação Biblioteca Nacional). Em 2003, publicou o livro de poemas Trecho (Aeroplano/ Fundação Biblioteca Nacional) e o poema em prosa "Cegueira impossível" na revista Inimigo Rumor n²14 (7Letras/ Cosac\&Naify/Livros Cotovia).E-mail:marceloebia@uol.com.br.

\section{Resumo}

Este texto pretende conceber um registro não-literário como um espaço literário, a partir da interpretação de uma entrevista concedida pelo poeta Armando Freitas Filho. Se a entrevista, a princípio, oferecese à fantasia da intersubjetividade e da apreensão imediata do sentido, ainda mais em se tratando da entrevista de um autor de uma obra literária, a entrevista de Armando parece configurar-se como um exercício de resistência à fantasia, expandindo o espaço erótico de sua própria obra. A entrevista, enfim, configura-se como o espaço de uma bio-grafia, escrita viva da experiência poética.

\section{Abstract}

This text intends to treat a nonliterary register as a literary space, through the interpretation of an interview given by the poet Armando Freitas Filho. If the interview, in principle, is offered to the fantasy of inter-subjectivity and of immediate meaning apprehension - even more in this case since the interview concerns an author of literature-Armando's interview seems to configure an exercise of resistance to fantasy, expanding the erotic space of his own work. The interview, finally, presents itself as the space of a bio-graphy, a live writing exercise of the poetic experience.

\section{Resúmen}

Este texto pretende concebir un registro no literario como un espacio literario, a partir de la interpretación de una entrevista concedida por el poeta Armando Freitas Filho. Si la entrevista, en principio, se ofrece a la fantasía de la intersubjectividad y de la aprehensión inmediata del sentido, aún más tratándose de la entrevista del autor de una obra literaria, la entrevista de Armando parece configurarse como un ejercicio de resistencia a la fantasia, expandiendo el espacio erótico de su propia obra. La entrevista, por fin, se configura como el espacio de una bio-grafía, escritura viva de la experiencia poética.

\author{
Palavras-chave \\ semiótica \\ poética \\ espaço literário \\ entrevista \\ Keywords \\ semiotic \\ poetic \\ literary space \\ interview
}

Recebido em

30/10/2002

Aprovado em

12/07/2003 